\title{
Computing, Social Activity, and Entertainment: A Field Study of a Game MUD
}

\author{
JACK MURAMATSU and MARK S. ACKERMAN ${ }^{\star}$ \\ Computing, Organizations, Policy, and Society, Information and Computer Science, University of \\ California, Irvine, U.S.A.
}

(Received February 1997; in final form May 1997)

\begin{abstract}
Are game and entertainment systems different than work-oriented systems? What drives the user's experience in a collaborative game? To answer these questions, we performed a participantobservation study of a combat MUD, a game similar to Dungeons and Dragons. Our interest is in how this social world is arranged and managed (rather than, for example, in how participants form or display individual identities). The study explores the social arrangements and activities that give meaning and structure to the participants. We found that conflict and cooperation were the dominant social activities on this MUD, much more so than sociability. The game's management played a critical function in maintaining and promoting these activities. Moreover, novelty and entertainment were important for the design of both the system features and the sociality itself.
\end{abstract}

Key words: Amusement, combat MUDs, CSCW, entertainment, games, MUDs, participantobservation, play, social worlds, system design

Almost all studies of CSCW systems have involved work-oriented systems. Indeed, work has been the major focus of computing for the last thirty years. However, as computing diffuses from the workplace into domestic environments, we should expect different types of use, such as systems for socializing or entertainment. We would expect, on the face of it, that system use and social activity for these collaborative non-work systems could be quite different from those found in workplace systems. Yet, surprisingly, there are few serious empirically-grounded studies of how entertainment or other domestic computing environments might differ from work-based computing.

One non-work use, already quite prevalent, is games, and these game systems are becoming increasingly collaborative. To study social activity on these systems, we examined a hack-n-slash MUD called Illusion. ${ }^{\star \star}$ Illusion, like most MUDs, was used by a varying group of players for most of each day. Unlike social MUDs, however, the game is the focus, and social involvement is consciously manipulated as part of the game structure. Players act together to play the game, both informally and formally. Yet, as we will demonstrate below, their social involvement with one

^ Co-equal authors. Author to contact: Mark Ackerman, Information and Computer Science, University of California, Irvine, CA 92797. E-mail: \{ackerman, jmurmat\}@ics.uci.edu. Url: http://www.ics.uci.edu/CORPS/ackerman.html.

$\star \star$ The name of the MUD has been disguised. 
another is quite limited in important ways, ways that may constitute an important class of Internet sociality.

This study, part of a larger study, is based on participant-observation occurring over a six-month period. Initially, our goal was two-fold. First, we wished to see the types of social interactions on these systems in our continuing study of virtual collectivities. ${ }^{\star}$ Second, these combat MUDs are relatively simple technically, and we believed we could observe the effects of using technically-wired rules to constrain and promote social interactions.

As we observed Illusion, however, it became clear that social activity was influenced by two other key elements in addition to the hard-wired rules. One, the role of a management layer, is prevalent in many computer-mediated communication systems, but has not been extensively studied. The second was the explicit goal of entertainment (or amusement).

This paper, then, investigates non-work computing, by examining the social activity and interactions on one such game system. Our interest is in how this social world is arranged and managed (rather than, for example, in how participants form or display individual identities). Accordingly, we first present the background literature for understanding MUDs and specifically game MUDs. The paper then surveys this social world, examining the various types of social structures that persist and the social activities that occur. We then detail two types of social interaction, first discussing the cooperation and sociability that occur on Illusion. We follow this with an examination of the conflict that occurs, in particular player killing. Finally, we conclude with some observations on the roles of entertainment, management, and a technical base in this social world.

\section{MUDs and games as social worlds}

A number of research bases are appropriate for studying combat MUDs. These systems are of course MUDs, and more broadly they are also computer-mediated communication (CMC) and collaborative systems. They involve games, and more broadly play and entertainment. We cannot hope to adequately cover each of these relevant literatures here; this section surveys some of the work that we found particularly important to our study's topic. Before surveying these literatures, however, we first present our general viewpoint, that of social worlds.

\footnotetext{
* We use the term "virtual collectivity" instead of "virtual community" to remove many of the connotations of "community" from consideration here. While we find discussions of what constitutes a community to be of interest (e.g., Mynatt et al., 1998 this volume), we did not want to exclude virtual collectivities such as Illusion from our overall work because they did not fit some notions of "community". We also note the vast number of definitions of "community" available, all of which seem to have positive connotations (Williams, 1985). Our interest in this paper is to describe how Illusion functions socially, regardless of whether it constitutes a "community" or not. Hence, we wish to bracket off the issue of community, and we use the terms "virtual collectivity" and later "social world" as being more general. After Illusion is fully described, the reader should be able to tell whether it fits his or her notions of community.
} 


\subsection{SOCIAL WORLDS AND SOCIAL ACTIVITY}

The Chicago School of Sociology's view of social activity frames this study. Foremost, it will be our argument that these systems constitute social worlds, albeit worlds of a particular nature. For both first-generation and second-generation members of the Chicago School, social world has served as a particularly durable concept. ${ }^{\star}$ Cressey, in his 1930's examination of dance halls (Cressey, 1969), offered a classic definition:

For those who attend the taxi-dance hall [Cressey's particular focus], even irregularly, it is a distinct social world, with its own ways of acting, talking, and thinking. It has its own vocabulary, its own activities and interests, its own conception of what is significant in life, and - to a certain extent - its own scheme of life. This cultural world pervades many avenues of the habitué's life ... (p. 31).

First-generation Chicago School members were particularly interested in observing a range of these social worlds, much like anthropologists examining foreign cultures. To the Chicago School, the newly emerging neighborhoods, occupational groups, and other groupings in the city offered new-found opportunities to observe social behavior. (We may have a similar opportunity today with the Internet.) Second-generation and later members deepened this interest into an examination of the details of social interaction:

In a sense, commitments to a social world as such are also the basis of Hughes' notion of a "going concern" in which certain assumptions about what activities are important and what will be done can be taken for granted (Clarke, 1991, p. 131).

A thorough review of the Chicago School emphases in examining social worlds are beyond the scope of this paper. (For histories of the Chicago School, see Bulmer, 1984; Fine, 1995. Critical reviews can be found in Strauss, 1993; Meltzer, Petras, and Reynolds, 1977.) Several points, however, deserve to be mentioned. The Chicagoans emphasized, following Dewey, Mead, and Cooley, that communication was key to human activity and that symbolic representation underlay human communication and interaction. Because shared meanings were therefore required for human activity, the individual necessarily had to form and then later exist within a social environment. For this reason, Chicago School scholars did not make a

\footnotetext{
* We recognize that it is a simplification to discuss the Chicago School as a single, decontextualized entity. Even the first generation (Park, Burgess, Thomas, Wirth, and Hughes among others) had its varying viewpoints, and the second (Blumer, Strauss, Goffman, Becker, and Fine among others) certainly did. (Even the location within these generations of Hughes, Blumer, and especially Goffman is controversial.) The argument also leaves out important interactionists who were never affiliated with the University of Chicago or its students. Nonetheless, this reduction makes the presentation considerably simpler, and recent work analyzing the Chicago "tradition" (e.g., Strauss, 1991; Fine, 1995) argues that such a reduction can be intellectually useful.
} 
clear distinction between their micro-sociology and social psychology (Collier et al., 1991).

They also de-emphasized distinctions between process and structure in analyzing interaction, as Strauss points out:

Chicago interactionist sociologists .... adopted nondualistic and sometimes explicitly antidualistic stances toward specifically sociological issues. Some of those stances are not unique to this tradition, being shared by other schools of thought and inquiry. .... For example, [they rejected] making a distinction between society and the individual, or between structure and process ... (Strauss, 1993, p. 45).

A Chicago interactionist, then, emphasized the fluidity and complexity of social phenomena, without stressing either the effect of structure on the individual's actions or the effect of the individual on social structures. This emphasis is quite critical for on-line worlds, with their multi-tiered structures (e.g., hard code, interpreted code, social structures) and quickly emergent behaviors.

Finally, Chicago School sociologists would also note the importance of an activity's context for the activity itself. The following statement by Strauss suggests why a given MUD system might offer a particular type of social world:

... specific instances of work activity always take place within some context that influences how the activity is carried out, by whom, for what purposes, when, and with what consequences (Strauss, 1993, p. 84).

If one omits the word "work" from this statement, the context of any social activity is key. We would expect that entertainment and play will have a critical role in social activity on a combat MUD.

\subsection{AMUSEMENT WORLDS}

Since the context of social activity is critical, we use the term "amusement world" to denote social worlds with their basis in play and entertainment. (We deliberately invoke the metaphor of amusement halls and amusement parks to remove some of the pejorative connotations of entertainment activity in the US.)

A great many social worlds have their primary purpose in entertainment and amusement, including game parlors, gambling casinos, amusement parks, hobby clubs, and the like. These are all places where participants come to the collectivity for a managed social world, and where participants expect to be entertained in some fashion.

While games have been extensively analyzed and cataloged (e.g., Avedon and Sutton-Smith, 1971; Crawford, 1984; Sutton-Smith, 1976a, b) and their role in play examined (e.g., Erikson, 1975; Schwartzman, 1978), there are relatively few studies of social worlds that focus on games. Fine (1983) studied role-playing games as social worlds. He studied both the social world of a role-playing club, as well as the social worlds of specific game groups. (He calls these small-group 
social worlds "idiocultures".) Much of Fine's analysis, however, concerns how participants move between the awareness contexts of game and real-life. Hayano's (1982) delightful little ethnography of poker players details the rich social world of Gardena, California's poker halls. He details the social organization of playing the game, as well as the groups, roles, and beliefs of the participants. In his study, Hayano shows how the social world of professional poker brings meaning and structure to its participants' actions. (It should be noted that we did not find any professional MUD players, although some might claim to be semi-professional based on their time commitment to MUDding.)

A larger number of studies examine social worlds that center on sociability; these social worlds include bars, neighborhood social clubs, restaurants, virtual communities, and social MUDs. (Although these worlds also entertain, and amusement worlds also promote sociability, we feel the emphases are different.) Because these have been more extensively studied, and also provide social activities under managerial control, we have found several particularly useful. Anderson (1978) studied a south-side Chicago bar and its social interactions. Participants in his bar's social world mutually defined and reinforced one another's identities and statuses. Katovich and Reese (1987) focused on interactions among bar "regulars", noting that largely separate groups come to a bar to drink and others to game. Other studies of bar and drinking behavior include Cavan (1966) and Roebuck (1986). Studies of dance clubs and their social worlds include Cressey (1969), Prus and Irini (1980), and Meckel (1988).

Many studies have examined CMCs and at least aspects of their social worlds. For example, the social world of an organizational distribution list was reported in Sproull and Kiesler (1991), the norms of use and social maintenance within a chat system was studied in Ackerman and Palen (1996), and a synchronous chat system used primarily for sociability was studied in Correll (1995). Correll (1995) is representative of a range of CMC studies (e.g., Jones, 1995; Smith, 1993). It draws on interactionist themes to examine the social construction of norms and a typology of patrons, while it also draws on CMC themes to include the construction of shared "bar" artifacts and the examination of community. For example, the study's main finding is that the bar's "primary function is to serve as a lesbian community ..." (p. 282). A growing number of CMC studies have examined virtual communities and detailed their interaction patterns. We cannot hope to fully review this literature; partial reviews of this literature can be found in Wellman et al. (1996) and in Cherny (1995). The next section, however, reviews the literature on MUDs in detail.

\subsection{MUDS AND SOCIAL ACTIVITY}

Only a handful of studies exist for MUD systems. Bartle (1990), in his early study, surveyed British MUDs and provided a rudimentary social analysis of MUD 
activity. As he reported, MUDs (or as he termed them, Multi-User Adventures or MUAs) are social worlds designed for game play:

From the players' point of view, the underlying mechanisms are of little or no interest. To them, MUAs are environments where things happen. Players have 'personae', which exist in a world elsewhere. ... MUAs are sprawling landscapes, richly described, and you can try anything (within reason) that you like (p. 8).

Game play, even in this early report, ranged considerably with a wide variety of themes and goals. For example, he noted:

Fighting is part and parcel of most MUAs, although some deliberately omit the concept, either for programming reasons, moral reasons, or both (p. 9).

Later studies largely examine social MUDs and MOOs (i.e., those MUDs with a primary goal of socializing or role-playing). Curtis and Nichols (1993), for example, provides an overview of MOO capabilities and their first-person experiences in creating and maintaining one. Turkle (1995) and Bruckman (1992) emphasize identity formation on social MUDs and MOOs. Rheingold (1993) provides a more popular exposition of the same themes of identity formation, including the issues of multiple identities, text-based behavior, and gender swapping.

Four studies examine the social worlds of specific MUDs. Reid (1994) extended her earlier work on IRC (1991) by examining how MUD users come to understand one another through text and participate in sense-making. Reid did study one game MUD, but provides only a general, although useful, overview of that game MUD. Although she notes it was dissimilar from her three social MUDs, the paper's emphasis falls on the similarity in virtual sense-making across MUD varieties. We extend her arguments on the dissimilarity of game NMDs, and also examine the social structures and activities of a specific game MUD through participantobservation.

Ito, in published (Ito, 1997; Mynatt et al., 1997) and in unpublished (Ito, 1994, 1995) work, examined "Farside", a combat MUD. Her emphasis in Ito (1997) is on the interplay of virtual fantasy and real life, arguing that they cannot be separated from one another. In earlier work, she focused on identity formation, but also noted the sociability of combat MUDs. We extend her early description of combat MUDs by detailing the social world of one of these MUDs.

O'Day, Bobrow, and Shirley (1996) studied the "Pueblo" MOO for an elementary school-centered learning community. (Pueblo is further examined in O'Day et al., 1997 in this volume.) They examined how technical and social conventions and mechanisms tradeoff and evolve. They found no simple relationship between technology and social mechanisms, but rather a co-evolution using what participants felt were appropriate measures in the situation. Our work shares their concern for how social and technical mechanisms interact, as well as their interest in examining co-evolution. We add an examination of a very different system and its social world. 
Cherny's (1995) finely etched ethnography details the culture and social structure of "ElseMOO", although her major emphasis is on the linguistics of this MUD. Her work (as well as that of the other authors mentioned so far) stands in marked contrast to the findings presented here. We share Cherny's basic concern with detailing a specific MUD and its social world. However, ElseMOO, being created as a social and sociable world, displays a much larger range of behavior and a much lower emphasis on amusement and entertainment than we found on our game MUD.

In addition, several unpublished works by participants (e.g., Masterson, 1994) and a handful of popular works on game MUDs exist (e.g., Shah and Romine, 1995; Busey, 1995). To our knowledge, there are no other studies of game MUDs, and no detailed, empirical studies in the published literature of game MUDs and their social activity. Accordingly, the subsequent sections examine the social world of one such game MUD.

\section{The game}

To examine social activity on a hack-n-slash MUD, the first author spent six months as a participant-observer on one such system. Illusion was only three months old when observation began, but already had approximately 20 players online at any given time. ${ }^{\star}$ Illusion, like many hack-n-slash MUDs, is based on a medieval fantasy world similar to that found in a Dungeons and Dragons game.

The system was picked for its underlying code base and its newness. ${ }^{\star \star}$ As the study unfolded, we were pleasantly surprised at the effort that the administrators put into constructing the world. It is possible to play the game for several months without exploring large portions of Illusion's virtual geography. ${ }^{\star \star \star}$ It also has relatively few "stock" (or generic) areas and game elements.

The work reported here is part of a larger study examining similar systems. In addition to the work reported here, we have also conducted a number of semistructured interviews with game players and administrators from various combat MUDs. These interviews used a derivative of think-aloud protocols (Lewis, 1982)

\footnotetext{
* Unlike the combat MUDs discussed in Mynatt et al., 1997, Illusion is available 24 hours per day, although it is occasionally down for up to a week.

Because of the system's features, it is impossible to know demographics with any certainty, nor can we fully distinguish players when they have several characters. We estimate that 60 to 75 active or marginally active players login during any given week. The majority of membership appears to turn over in six months. Unlike some other combat MUDs, Illusion does not have penalties for inactive characters, and some players and their characters login occasionally. Most players seem to come from North America, with only a handful of participants from Europe. We believe that membership is heavily skewed towards college-aged males.

$\star \star$ Illusion was based on Merc code, which is in turn based on Diku code. Both are standard code bases for game MUDs. Over the course of the study, however, Illusion was heavily customized by its administrators. In addition, to our knowledge, all of the "area" (i.e., zones or clusters of rooms) are original to Illusion. Nonetheless, Illusion bears a considerable resemblance in general to other Dikus. $\star \star \star$ While many combat MUDs may have five or so areas, Illusion has over twenty. It has thousands of rooms.
} 
designed to elicit social information from interviewees (rather than cognitive or usability data). While we do not report on these additional data here, they allowed us to conduct a much shorter period of participant-observation than we would otherwise have needed.

The logs of the participant-observation, as well as fieldnotes, were subjected to a standard ethnographic analysis (as outlined in, for example, Strauss, 1987; Miles and Huberman, 1994). Both authors had access to the logs and fieldnotes. A range of secondary material, including code bases, help files, web pages, background stories for the MUD and its groups, and bulletin board messages, were also used.

All names and identifiers have been changed in all data provided here to allow anonymity for the users, their characters, and the site. We have occasionally corrected spelling and grammar, and this publication has reformatted the logs for readability.

\subsection{PlaYing THE GAME}

Playing the game is the central experience on Illusion. Below, excerpts from one session's field notes provide some of the participant's experience. Although most of the terms will be unfamiliar to readers (and will be explained in this and subsequent sections), the field note gives a general overview of game activities.

Below, the character Durendal interacts with a number of other characters, although he is playing the game by himself.

I $\log$ on to Illusion, and check the "who" list to see who's around ... Send a public hello over OOC [the Out-Of-Character channel]. Torch says that the desert might be good killing for someone of my level ...

Durendal decides to hunt "mobs" (or mobile monsters), the central opponents in the game. He goes off to a new area of the game to do so, but he finds it difficult:

The desert. Never been in this area. Need to try to figure out what to kill. Hope I can kill these mobs on my own - soloing's pretty tough for thieves. Hmm, a nomad. I wonder how tough these mobs are. Con [the "consider" command] indicates "easy kill".

[I type] "Kill nomad" - my backstab misses. I might be in trouble. Backstab does a lot of damage and without it fighting is difficult - it's a one-shot deal. I'm taking way too much damage here.

Auto-flee! I lost a bunch of hit points and have no experience points to show for it.

Finally, Durendal gives up on his hunt for mobs and decides to return to the town, which is the central point in the game's virtual geography. He finds other characters there, and the field note ends with Durendal wondering whether he should team with another character to fight mobs: 
Finally. Ok, turns out the only thing I can kill here are the scorpions. . . . No point hanging out here - I certainly don't want to get stuck out here. I'd eventually run out of food or water and die.... Back in town at the fountain. Gandalf leaves. Katana and Kaos are chatting here at the fountain ... Hmm, the desert wasn't very cool by myself. Maybe Katana will go out to the desert with me.

In the above excerpts, Durendal is largely engaged in hunting and fighting "mob" by himself. He also considers whether he should join with another character to fight mobs. This highlights the primary activity on Illusion - fighting these system creatures while simultaneously exploring the world. Players spend most of their time hunting down and killing mobs in order to "level", or advance to the next level. As a character advances to the next level, he is rewarded with incremental improvements in capabilities and power (e.g., hit points, additional skills). The higher the level of a character, the more formidable an opponent he will be to both mobs and other players. As might be expected, the higher the level the more difficult it is to advance to the next level, increasing the challenge to the player. Perhaps as a result, levels are often measures of prestige or status for players. In fact, in the absence of other information about a character or the player behind the character, a character's level alone may be sufficient to command respect from other players.

This game play cannot be separated from the pace of activity on a combat MUD: Events fly by at a frenetic pace. The descriptions of rooms, players' activities, and mobs' actions rush past, at times almost too fast to follow. Moreover, one must constantly track everything. One must remain constantly vigilant: System features, mobs, and even the other players can be hazardous. This frantic pulse to the game activity provides much of the excitement and rush for the players. On the other hand, from time to time, a player finds or creates a lull to relax and chat about the day's game with other players. At quiet moments, banter about the game play, one's actions, and ones' scores predominate.

Figures 1 and 2 show two sample screens from a user session. These are typical screens from a relatively uneventful portion of a session. In Figure 1, the user is merely moving from area to area, invoking textual descriptions of the scene. In Figure 2, the user engages a monster in a fight; this is a particularly short fight (for reasons of space). Figure 2 also shows the use of the Out-Of-Character (OOC) channel, a public channel also mentioned in the fieldnote above. In practice, these two screenfuls would scroll by rapidly in a tty window, perhaps using boldface and color to emphasize names and certain play elements (e.g., new monsters showing up in the area). Beginning players (and perhaps the reader here) might find many of these terms and situations unknown and potentially confusing; learning their meaning (while frantically trying to stay alive) is part of the game experience.

Some players use a game client that can react automatically to certain conditions, such as tintin or zmud. Other kinds of robotic clients are explicitly forbidden in Illusion, leaving the player to his own wit and skills. 


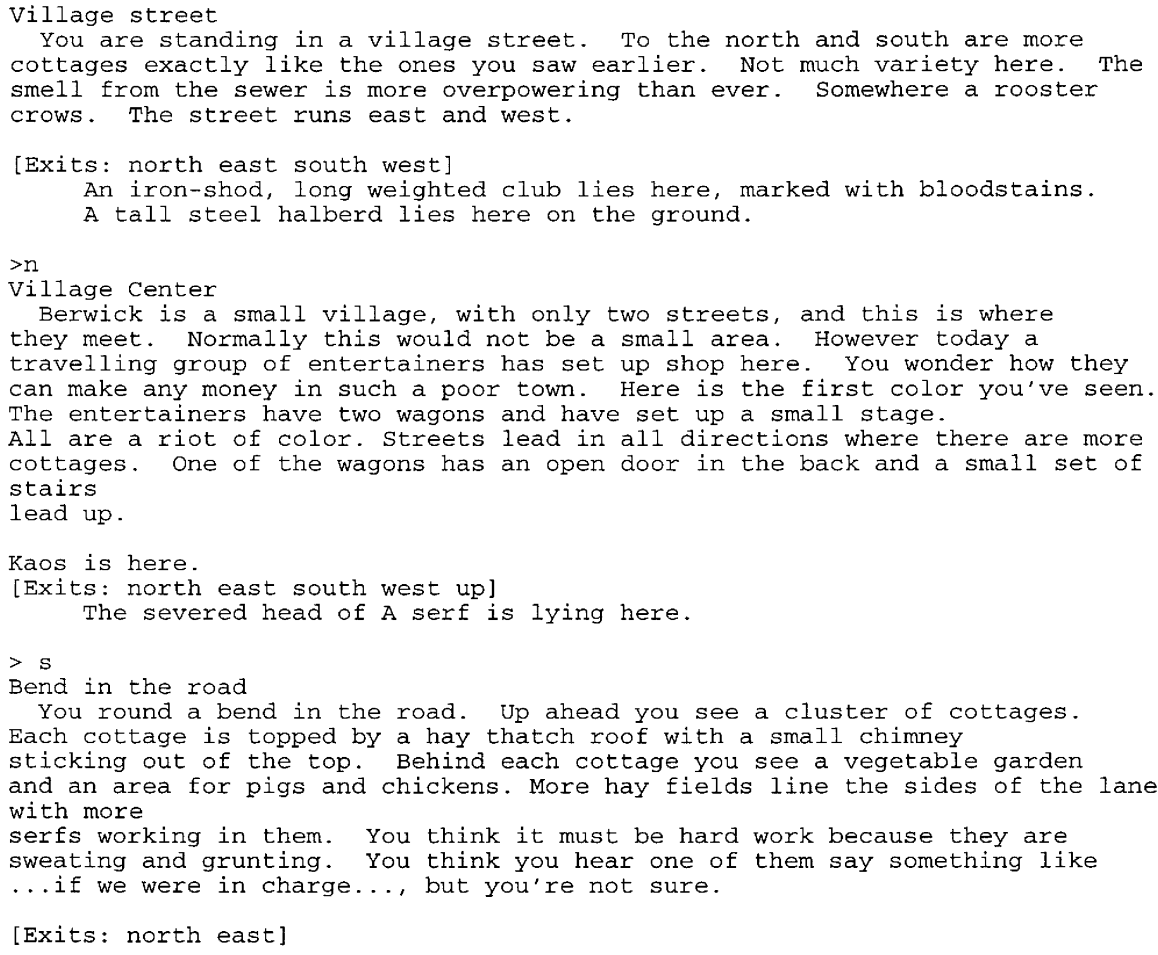

Figure 1. Area descriptions.

\section{Combat MUDs as social systems}

Illusion is not merely individual play; the social world is an explicit part of the game. Forms of social life add additional flavor and urgency to the game. Yet, for reasons that will be discussed more fully after describing these social elements, Illusion is a specialized social world, one wrapped around its game function.

\subsection{PlaYERS, CHARACTERS, AND SOCIAL ROLES}

Before detailing the social interactions and social structures that exist in Illusion, it is necessary to describe who inhabits this social world. In Illusion, there are two types of characters, "mortals" and "immortals". These two character types play very different roles on the system. The MUD is deeply socially stratified, with players both informally segregated by game levels and formally segregated by their power to control the system. While mortal characters are generally concerned with playing the game per se, immortals take responsibility for maintaining, shaping, administering, and policing the MUD. Most players on Illusion have only mortal characters. (It should be noted that players can, and do, have several characters, 


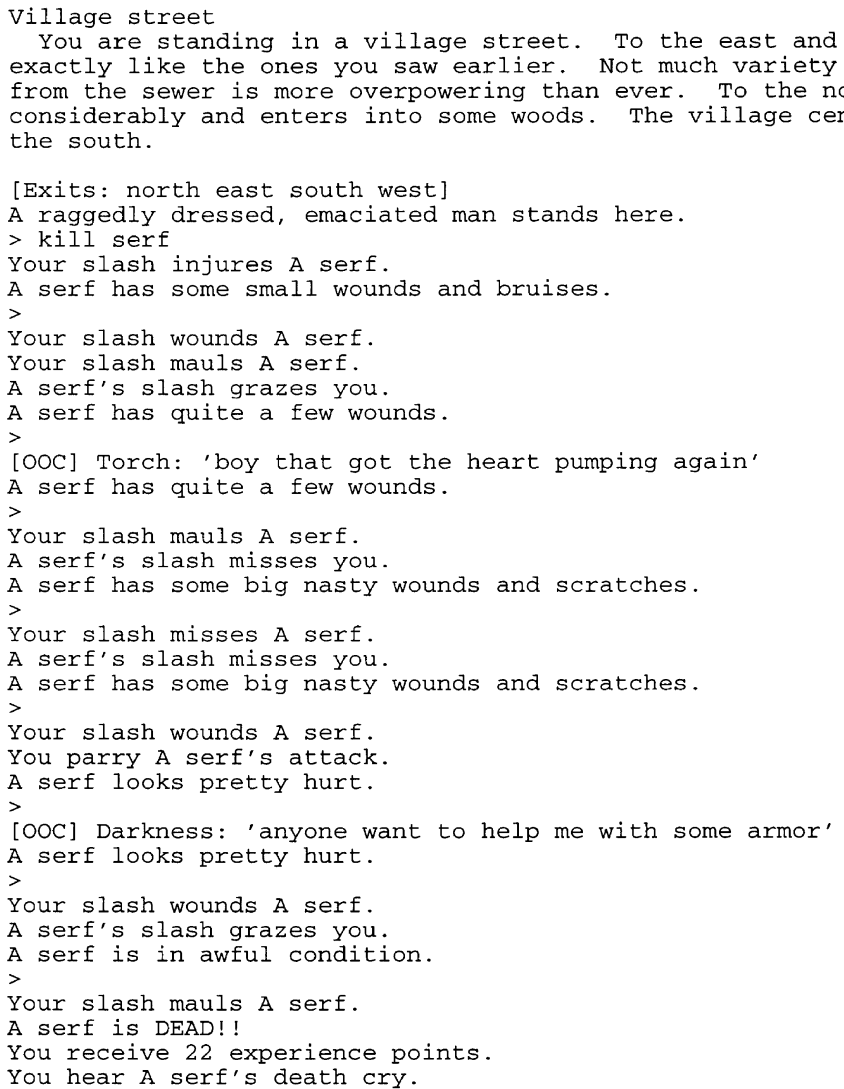

Figure 2. A combat with a system-controlled mobile ("mob").

although the immortals strictly enforce players' using only one character per game session.)

In general, the immortals have abilities (e.g., capabilities to change the MUD) that mortals do not have. In a strong sense, immortals have both status and power within the MUD world. As mortals advance in level, they gain status among the lower-ranked mortals; however, they have little authority or power.

\subsection{MORTALS}

Nearly all the characters on a combat MUD are mortals, characters who are involved in the social world by playing the game. Illusion is no exception. Mortals are primarily concerned with playing the game: ${ }^{\star}$

\footnotetext{
* In the following log excerpts, we have provided only the communications between characters. If we did not do so, almost every log fragment quoted in this paper would run several pages. Also, the "someone" identifier does not belong to any one individual in these logs; it indicates that a character is invisible and therefore anonymous. However, within each log fragment presented here, we believe
} 


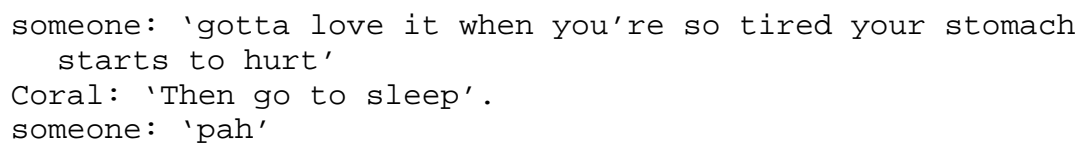

As mentioned, mortals are primarily interested in leveling, or advancing to the next rank of mortal:

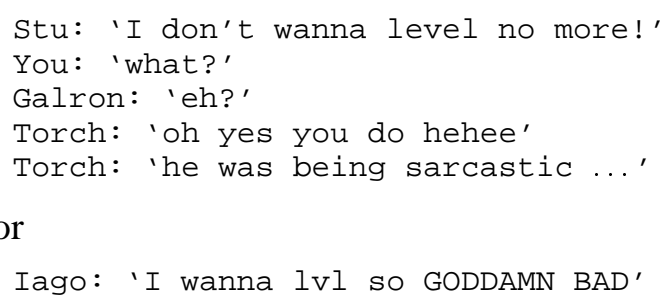

Iago: 'I wanna lvl so GODDAMN BAD'

or

Indeed, players often announce their progress towards the next level to one another during grouping, largely because the levels are so important to why they are in this world. In the next exchange, "tnl" is an abbreviation for "to next level" and the numbers refer to the experience points needed to reach that level:

Hemlock: 'only 125 tnl'

Aegis: '51 tnl'

Within the game, mortal characters have specific attributes, chosen at their creation. In addition to being critical game features, these character attributes are key in many social interactions among characters. It is therefore important to briefly describe these character attributes.

On Illusion, the important three character attributes are class, race, and alignment. Class is a character's specialty or profession. On Illusion, the classes include warriors, clerics, mages, and thieves. Different classes have different roles and game powers. For example, warriors have better fighting abilities, and clerics have better healing powers. Since each class has varying powers, players often depend on other characters to provide various capabilities and skills that their character lacks. A potential ally's class may be just as significant as the demeanor or personality of the player behind the character.

On Illusion, a character can also have the physical attributes of, among others, a human, elf, or dwarf; these are called races. A character's race serves as one element that structures social interaction on Illusion. For instance, the Kalish are supposedly a militant race who do not get along with any of the other races. A player adhering to the norm of role-playing on Illusion (discussed further below) must act appropriately for the race's background story, origins, and relationships with other races.

Finally, alignment reflects a character's chosen demeanor - good, neutral, or evil. Good and evil characters are not allowed to group together informally on Illusion, thus limiting one's choices of allies. This is enforced technically.

that "someone" is only one person. That is, the "someone" identifier is a different person between presented logs, but not within each log. 
While class, race, and alignment directly structure the social role of a mortal character in this social world, there are other character attributes that contribute to the individual's overall "power" during game play. These attributes include strength, dexterity, intelligence, wisdom, charisma, constitution, and hit points.

Despite the large number of role-playing categories, the mortal role is not highly differentiated. Most mortals just play the game, often with a thin veneer of roleplaying. This can be seen in the following exchange, where one character (Sinjin) mocks the Brood, a group of humans and elves. The leader of the Brood, Khan, rises to defend his group. However, both players signal that they are merely role-playing. Note the use of the two channels, Gossip for game communications (including roleplaying) and Out-of-Character (OOC) as a back-channel for signaling intentions:

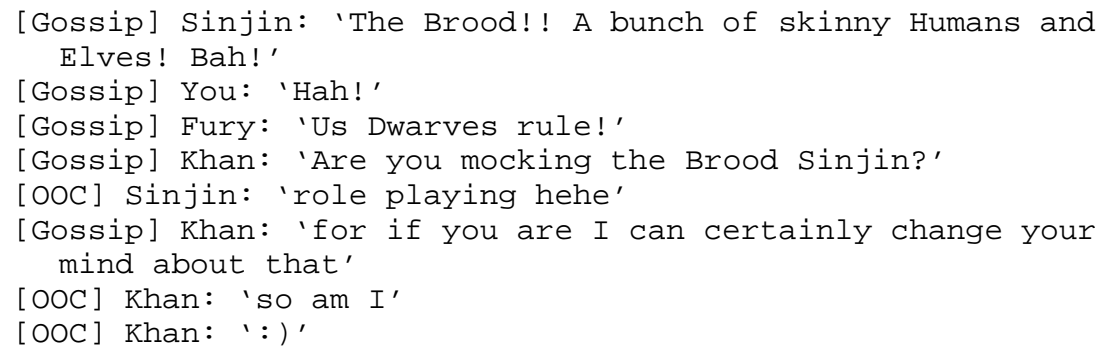

There are few informal roles, although some exist for higher-ranked mortals. Many experienced players will make comments and suggestions about Illusion publicly and in bulletin-board notes. A few high-level players will informally obtain equipment for lower-ranked mortals, either for free or for payment. High-level and mid-level players will occasionally help newbies (beginning characters). A handful of characters provide sociable comments over the public channels regularly (to be further discussed below). These sociable characters are generally high-level, as well as being the most long-term inhabitants. Also, those who are experienced on other MUDs will often publicly reminisce about the other MUDs, providing background context to newer users.

Not every experienced player accepts these informal roles. For example, some players who made private comments that they were extremely experienced did not offer any public opinions about the MUD, nor did they help newbies. Other high-level players, in fact, stole equipment from newbies or even killed them. Nonetheless, these informal roles seem to be relatively stable, and more than one mortal fills them.

\subsection{IMMORTALS}

As mentioned, the other major role on Illusion, as well as other hack-n-slash MUDs, is that of immortal (or "imm"). Immortals do not play the game per se; immortals are responsible for the management of the MUD. They create, administer, maintain, and organize Illusion. For example, immortals administer the rules, both in terms 
of creating the rules (e.g., by creating laws or by writing code) as well as enforcing them (e.g., by jailing mortals for a period of time).

Glyph: 'the stuff is enforced mostly by imms watching ya'.

The immortals are also responsible for technically running the system. Only immortals create objects such as mobs and equipment and place them in the game. They also create new system capabilities and bug fixes.

Illusion, like other combat MUDs, has a hierarchy of immortals, where each level of immortal has differentiated responsibilities for the MUD's management. The highest rank of immortal consists of "coders" (often called "imps" or implementors on other systems) who maintain and revise the MUD code as well as run the system. Only the two coders have access to the underlying code and data. Below the coders are the "regular" immortals (often called "caretakers" or "wizards" on other MUDs) who help mortal characters and provide general administration. Finally, below the regular immortals are "builders", immortals who create new game areas. During the study period, in addition to the two coders, there were six regular immortals and five builders. At least three of the regular immortals were charged with player relations, answering questions about the system, and fielding complaints.

The immortals command an absolute position in the status, authority, and power hierarchies. They solely have the power to control the game. They can change the scores and attributes (e.g., experience points, hit points, intelligence) of the mortals, they can destroy characters ("deleting"), and they can even banish players ("sitebanning"). As an indication of their power over mortals, immortals can "snoop" on mortals, thereby seeing what the mortal sees and types without the mortal's knowledge. As well, immortals can control which levels of mortals can see them, if any.

Unlike participatory or democratic governance structures on many social MUDs (e.g., LambaMOO), Illusion belongs to its immortals. This power is stated, implicitly and explicitly, over and over in the logs. For example, one mortal character explicitly remarks:

[Gossip] Firestone: 'any imms on we can grovel to?'

In another exchange, the power is acknowledged implicitly. In the following, Heimdall is an immortal; the others are mortal. The immortals' power is acknowledged humorously by Gandalf, when another mortal Redclaw challenges Heimdall's understanding of the rules:

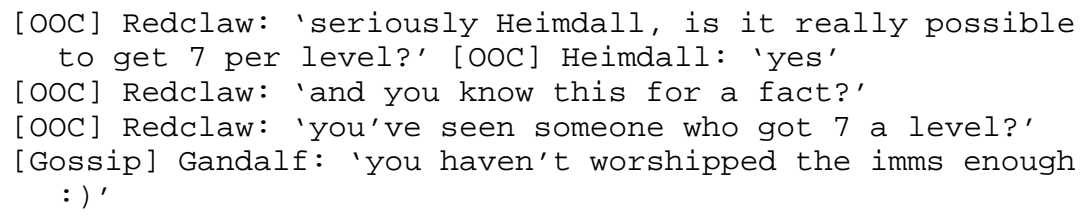

As mentioned, this power comes from the immortals' ability to save and reward mortals, although this is largely forbidden by Illusion's rules. However, the fear 
of an immortal's wrath may be more important, as evidenced in the following exchange. In this fragment, taken from a longer exchange, an unnamed immortal ("someone") jails Jersey for being rude to him or her:

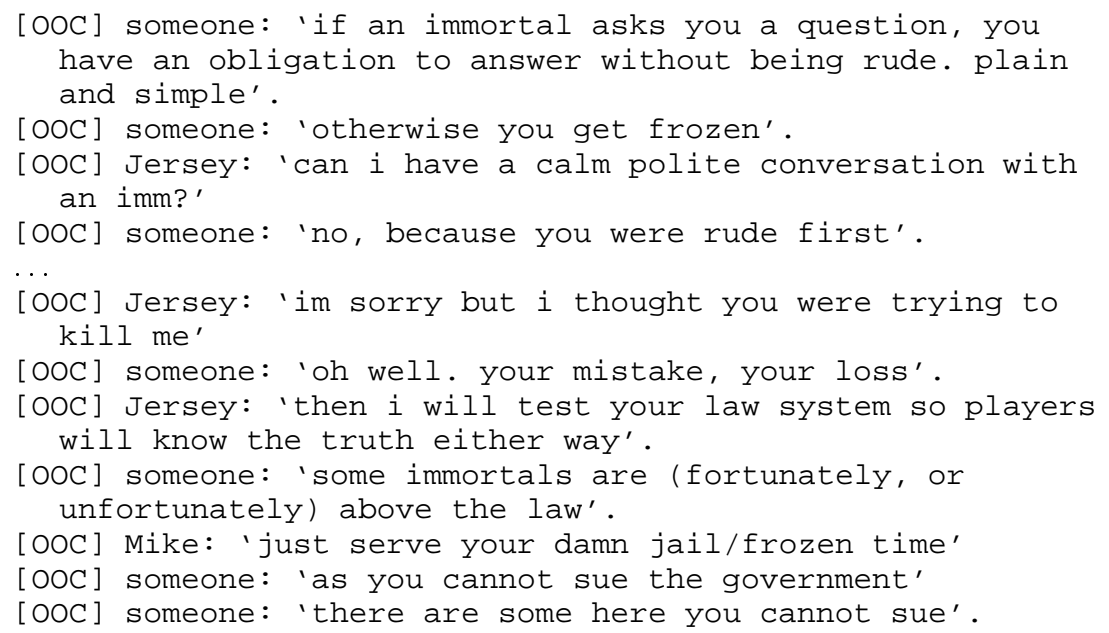

In a fundamental sense, the immortals manage the mortals. Mortals are free to act and interact, but only within the bounds specified loosely by the establishment's management, much like the participants in many commercial enterprises such as bars, hotels, or even bulletin-board systems. For example, in Katovich and Reese's bar (1987), the owner and bartenders set the rules for basic behavior in the bar - not any behavior was tolerated. Similarly, in Anderson's bar (1978), the owner Jelly set the basic rules; not even "regulars" could violate them and remain members of the collectivity. ${ }^{\star}$

In this sense, mortals are powerless; if they wish to remain on Illusion, they have to heed the immortals. And indeed, immortals can be rather capricious, as will be seen in the "clan" discussion below. However, some of the consequences of this power inequity are mitigated by the regulars' capability to take their business elsewhere:

[OOC] Iago: 'well, if they do too much of this bs people will leave the mud'

The management's power, then, also operates within a bounded, negotiated range determined by the co-operation of the MUD's prized regulars. These regulars self-regulate to some extent by making suggestions, pointing out other play-

\footnotetext{
* Many studies of commercial enterprises promulgating sociability and social interaction center on the customers, rather than the management. For example, Anderson's (1978), Cavan's (1966), and Katovich and Reese's (1987) studies of bars all have only cursory descriptions about management's role in their observed collectivities. Hayano's (1982) study of poker playing, Prus and Irini's (1980) study of a hotel, and Dunier's (1992) study of a Chicago restaurant all have less than a chapter on management. Nonetheless, all of these studies make it clear that the participants interact only within a range tolerated (explicitly or implicitly) by the management.
} 
ers' problematic behavior, and complaining about immortals' policies when they become too inconsistent, burdensome, or derogatory.

Outside of their power relations with mortals, we have very little data about the immortals' division of labor or informal roles, since the immortals' private communication channel was closed to us. We were able to observe only how they presented themselves to the mortals. (Indeed, mortals do not always even know when new immortals have been appointed.) It is clear that the immortals are occasionally divided in opinion and lack important knowledge about new directions and directives for the MUD. They thus show symptoms of being semi-professional or amateur management (like the game masters in Fine, 1983). There is some informal role differentiation that is apparent. One coder is clearly in charge of the MUD, although why this is the case is unclear. Several immortals occasionally send out messages praising Illusion; this is clearly beneficial for social maintenance:

[OOC] Soulfire: 'THIS IS THE ROCKINGEST MUD OF ALL TIME'

However, with such a small group of immortals, we follow Strauss (1991) that roles will be partially dependent on the specifics of the participants.

\section{Social groupings: Informal and formal groups}

For interactionists, structures are the enduring, "given" aspects or conditions of situations, the aspects we can bet with relative safety will remain basically "in place" and predictable for some time (Clarke, 1991, p. 129).

Hack-n-slash MUDs are not very elaborated virtual collectivities. (Their reliance on rudimentary social structures was one of the reasons we wished to study them.) Players buy and sell equipment, they have a court system, they form informal groups to hunt monsters ("grouping"), and they cluster into formalized groups ("clans"). Each of these provides occasions for social interaction, and each shows how social activity and interaction were built into the game as part of the game itself. We cover each in turn.

\subsection{MinOR SOCIAL STRUCTURES}

Swords, magic spells, clothing, and other equipment are critical to a character's power, and players expend considerable effort and time on their equipment. In addition to obtaining equipment from mobs, players can buy equipment from one another on the Auction channel. The selling, bidding, auctioning, and purchase are all done through the underlying system code. Although players need not interact about the auction, they occasionally request that special equipment be auctioned and ask questions about the available equipment. Auctions also serve as occasions for sociable interactions, as in the following exchange:

[Auction] Redwood staff sold to Gecko for 5000.

[OOC] Anastasia: 'Gecko, did you need it that badly?' 
Illusion also has a court, where mortals can be tried by their peers for rule violations. During the study, we saw the court used only twice, both at the beginning stage of our observation. (A snippet of one trial is provided below.) The court system appears to be moribund, perhaps because of the management overhead of running a trial. There does not appear to be any technical support for trials.

\subsection{GROUPING}

While it is possible for an individual player on Illusion (or other systems) to seek out and kill monsters alone in the hopes of leveling ("soloing"), this approach is often very time-consuming and difficult. Therefore Illusion and other MUDs allow players to form an adventuring group to collectively kill mobs as a unit. These informal groups are called "groups", and the activity is "grouping":

[OOC] Braveheart: 'anyone out there want to group and help me level'

The centrality of leveling to grouping can also be seen in what participants call strong groups - "leveling trains". Grouping allows players to combine their characters' combat skills and pool the differential capabilities of different character classes. Since mortals can thereby use conventional as well as magical attacks, for example, on a given monster, mortals often group to attack mobs that are hard to kill. Not only do they increase their chances of survival, they also level faster, as they gain experience points for successfully killing the mobs.

Grouping is critical to the MUD's social activity. In addition to character advancement through group efforts, grouping also provides a more intimate forum for socialization and sociability. Instead of merely observing others' behavior on public communication channels or in brief glimpses when in the same room of the MUD, grouping with another player shows how that player reacts in tense, risky, and unclear situations - in short, in combat-type situations. Players come to trust (or distrust) one another while grouping, as they provide for one another, divvy up captured equipment and prizes, protect one another's corpses, and the like.

For example, in one episode Kaos, a character later site-banned as a problem, was not getting the rewards he thought he deserved from grouping. He decided that the problem was that another character, Anastasia, had a falcon (essentially a special mob in the service of a character) and that the falcon skewed the complicated algorithm used to divide rewards. Kaos tries to convince Durendal, the third character in the following excerpt, to kill the falcon against the wishes of Anastasia. When discovered, Kaos denies the situation, showing an aspect of his personality. Also note that this excerpt shows one of the major technical supports for grouping, a separate communication channel for group members. Kaos and Durendal are using a private channel (in the lines with "tells"), and all three are using a group channel (in the lines with "tells the group"). The plot to kill the falcon becomes known to Anastasia because Durendal sends his private message to the group channel by accident: 


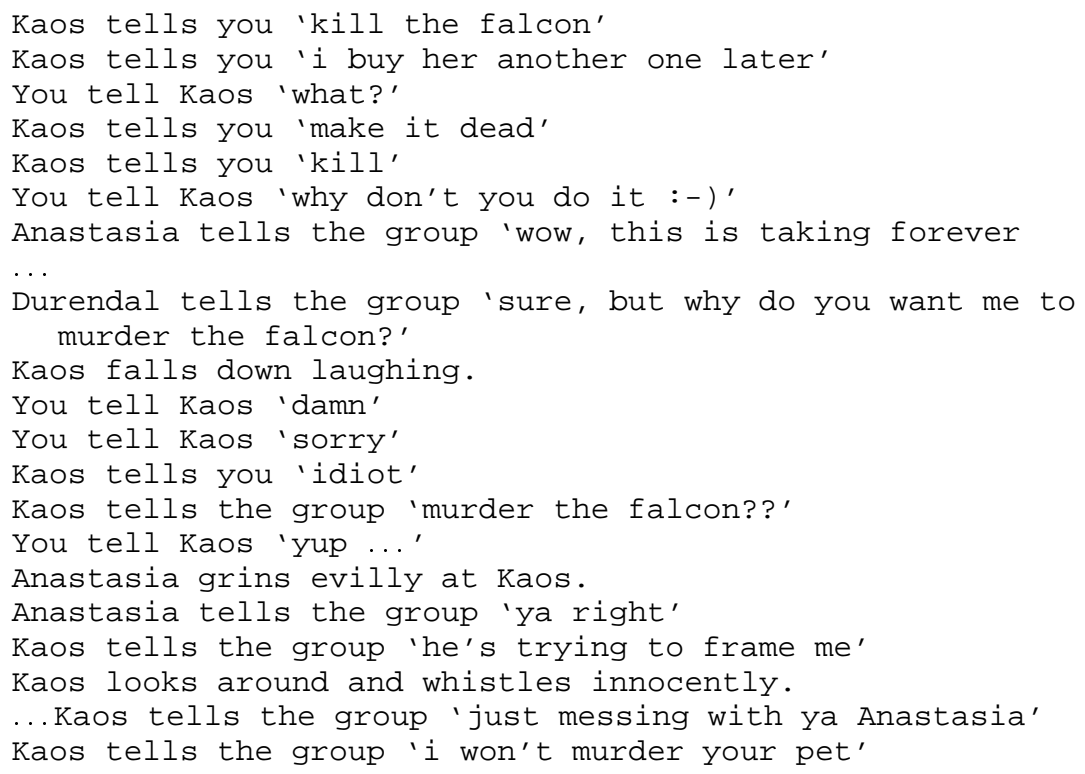

In addition to supporting group communications through the group channel, the system also allows people to attach themselves to a group, to automatically follow one another, and to automatically attack with other group members. As well, the system automatically allots rewards from group kills. Technical support for grouping is therefore rudimentary, and once people are in a group, there are few constraints on (or supports for) their behavior.

Because of the group channel and shared activity, grouping provides a smallscale forum for personal interactions. The following shows merely how two individuals divide the spoils of an attack; this becomes the basis for further joint interaction:

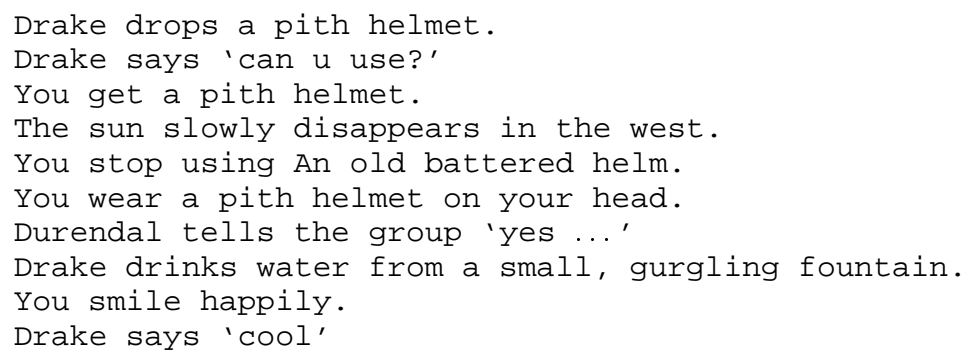

Grouping also provides socialization to the norms, techniques, and lore of the MUD. While in a group, there is a greater opportunity to observe others' behavior, explore new areas of the MUD, and ask questions. Coming to know the location of things is very important. One of the central features of group leaders is that they know where to find appropriate targets. Moreover, understanding the intricate relationships among pieces of equipment, skills, targets, and game play requires a 
considerable amount of explanation and elaboration by more experienced players. In many situations, players learn from one another how to play the game.

While knowledge of locations and game play is provided publicly over the standard channels (and is a standard form of cooperation), considerably more of these interactions occurred within groups. In addition to learning the limits of acceptable behavior by asking questions and watching others, one also can learn about the limits and advantages of one's own identity within these more intimate social groupings.

It should be noted that group membership and group leadership are extremely fluid. It is common for leadership to change during a grouping, and members come and go as well. Furthermore, groups last only for a single session. However, there is some regularity with whom one groups. Because of technical restrictions on allocating rewards and on alignment, it is most advantageous to group with others close in level and alignment. Since characters gain levels through grouping and accordingly a group of characters gains levels at a common pace, cohorts form. These cohorts range across character attributes, because of the advantages of fighting with diverse classes and skills, but not across levels, alignments, and to a lesser extent, races. The combination of restrictions and fluidity in grouping no doubt furthers the lack of specific roles within groups, leading instead to characters (or players) establishing reputations (or "reps" in Suttles, 1968).

Non-game conversation within groups was rare in our observation. The game activity in grouping largely prevents much sociable interaction. Activity within groups is split into two phases in an alternating cycle, the "kill" phase and the "sleep" phase. The kill phase revolves around combat and travel during which a player's screen scrolls at a very quick rate. The fast scroll rate coupled with the need to attend to battles tend to discourage conversations between players during this phase. It is very difficult to read a message uttered by a player during combat. After sustaining a certain amount of damage (determined by game algorithms), characters are forced to sleep. The sleep phase has a much slower pace and typically involves waiting while the system progressively "heals" characters. Healing occurs at regular system defined intervals ("ticks") usually every 45 to 90 seconds. Most conversations among group members take place within these three or four minutes. The majority of these conversations focus on game play, often recounting game experiences. In our experience, there is very little discussion of players' outside lives, and personal disclosure is kept to a minimum. Within a few minutes, game play continues as a new kill phase begins.

In summary, then, grouping provides a more intimate forum for game play, and its social character is an intrinsic part of the game play on Illusion. Since grouping is critical to successful leveling, it can be safely said that one cannot play the game successfully without engaging in at least limited social interaction. 


\subsection{Clans}

Clans (sometimes called "guilds" or "empires" on other MUDs) are more complex social formations than are groups. While groups are temporally limited to a single game session, or part of one, clans persist across sessions. Groups typically include two to six players; clans may involve over a dozen active members.

Clans on Illusion have undergone a number of transformations under the direction of the immortals, as the clans figured prominently in the immortals' push towards greater role-playing. As we argued above, this role-playing is largely superficial. Nonetheless, role-playing's effect on clans has been significant, since who can join a clan is currently based on the clan's predominant race requirements. For example, the Kalish cannot clan with any other race, since supposedly they are hated by all other races. In a sense, segregation is currently an enforced game feature on Illusion. As immortals decided and redecided what constituted a "proper" clan, clans have been unstable, often being broken up after a few days or weeks. This process has often seemed arbitrary to many mortal players.

However, across all periods, clans have varied in their organization, significance, and influence within Illusion, based on the involved participants. Some clans are extremely cohesive, providing safety and material advantages to their members; other clans are loose confederations of barely interacting members. As an example of a cohesive clan, the Brood formed with most of the "cool" players on Illusion:

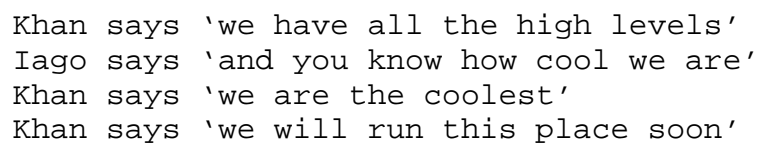

In the Brood, clan members gave equipment to one another, formed a clan hall for safety against enemies, and generally grouped with one another. At its best, a clan protects its members against player killing and other ills, as this example from the Maddogs (the precursor of the Brood) shows:

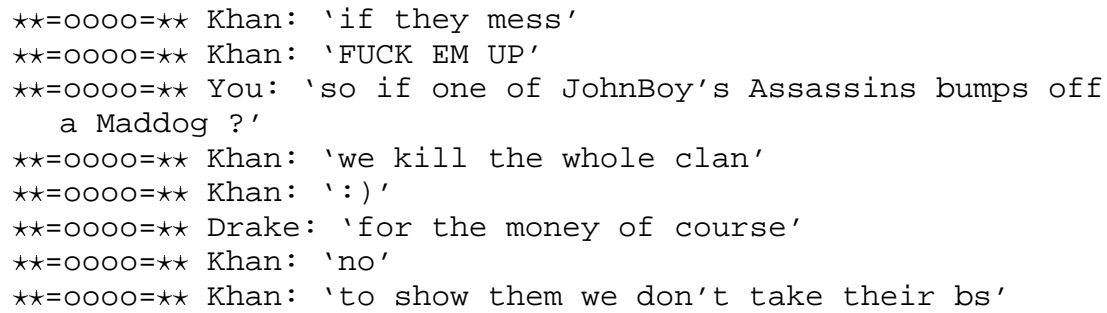

The above example also shows one type of technical support for clans: Clans have specific clan channels that are restricted to their members (shown by the ASCII figure at the beginning of each message).

The code base also supports clan leadership and an exclusive membership. In cohesive clans, as in other informal but cohesive groups such as gangs or corner groups (e.g., Conquergood, 1994; Suttles, 1968; Whyte, 1993), the clan leader generally sets up and informally enforces a clan "attitude". He or she also composes 
a clan myth and policies. Interestingly, what appears to be the most cohesive clan on Illusion, composed by Kalish who are outcasts in Illusion's role-playing, has an internal rhetoric of hostile others, a hallmark of strong gangs (Conquergood, 1994).

Clan leadership appears to be highly valued. It allows players to practice leadership and administrative skills in a highly restricted environment. In Davis' (1968) terms, clan leadership serves as role simulations for participants' future performances in professions and businesses. The following fragment shows Durendal practicing leadership in yet another clan ("xp" and "exp" refer to "experience points" or scores, and "cougars" are mobs):

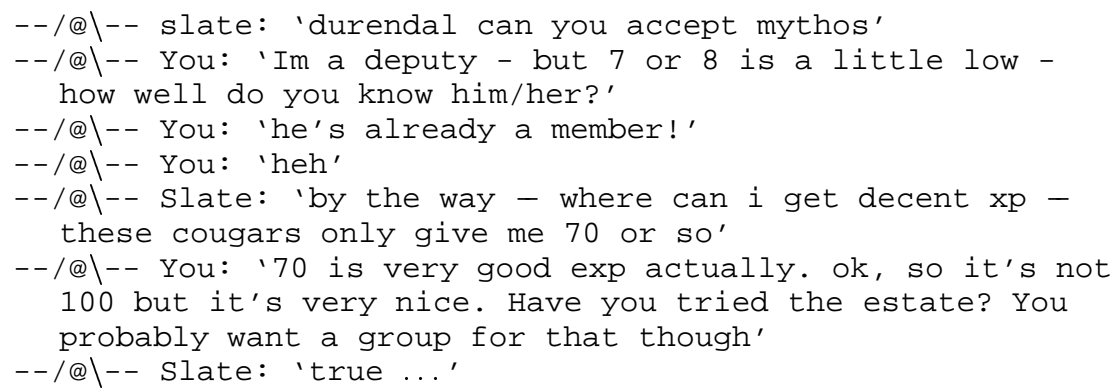

As the fragment shows, any clan member may take an active role in recruiting new members, but only the leader and deputies can formally accept the new member. Clan leadership is not fluid, generally lasting for the duration of the clan, even if the player seldom comes online. While a player can become the clan leader by killing the current leader, we have seen only one example of this during our observations.

The Illusion code base began with minimal support for clans, focusing on clan channels and on basic membership management (e.g., adding and removing members). Over time, technical support has become more extensive and clans more elaborated, with clan halls and clan wars. Currently, Illusion allows clans to purchase a clan hall. (On many other combat MUDs, a hall is provided to each clan automatically.) A clan hall provides protection and security for clan members, because it can serve as a safe haven for members who are being hunted by other players. Another function of a clan hall is to house a donation room or pit that can be used to distribute spare or unneeded equipment to other clan members. Clan wars allow clans to ally and battle one another.

A cohesive clan serves many of the social functions of a group. Like a group, it enables players to interact with other players in a restricted and protective environment, but it does so over an extended period of time. In fact, in cohesive clans, many groupings occur within clan boundaries. As with grouping, a clan also provides a forum for exchanging information about the game and its environment. For example, clan members may tell others about areas with the best equipment or that are too dangerous; much of this occurs over the clan communication channel. 
In our experience, clans that are not cohesive generally have few messages on their clan channel and little interaction.

\section{Sociability}

People know what to expect of one another in various social situations.... They learn what the social world is, what possibilities it contains, and what forms of conduct are permissible or unthinkable. They also learn how to recognize from the words and deeds of others what they are going to do and what they expect.

(Hewitt and Hewitt, 1986, p. 84)

The above sections showed that social activity had been designed into the environment to make it an intrinsic part of the game and of the social world. But for the users, the social world is not the social structures, it is what you do in the world. We have already alluded to many kinds of social interactions; for example, the cooperative acts in groups and conflicts between clans. This section and the next detail the interactions most often seen on Illusion. As we will show these interactions center on combat play and, perhaps surprisingly, are often shallow in nature. This section focuses on sociable interactions.

\subsection{PlayfulneSS}

As one might expect on a game system, social interaction among players is often playful and creative. For example, in the court trial of a renegade player for killing a newbie, one player in the "jury" created a fictional bottle of whiskey and passed it about the jury box. The following fragment is highly shortened from the original, but shows the playfulness of impromptu behavior on Illusion. Preia was the newbie victim, Redclaw is on trial for killing her, Sinbad is Redclaw's comrade in this adventure, Fire and Lorinda are jurors, and Heimdall and Soulfire are the immortal judges:

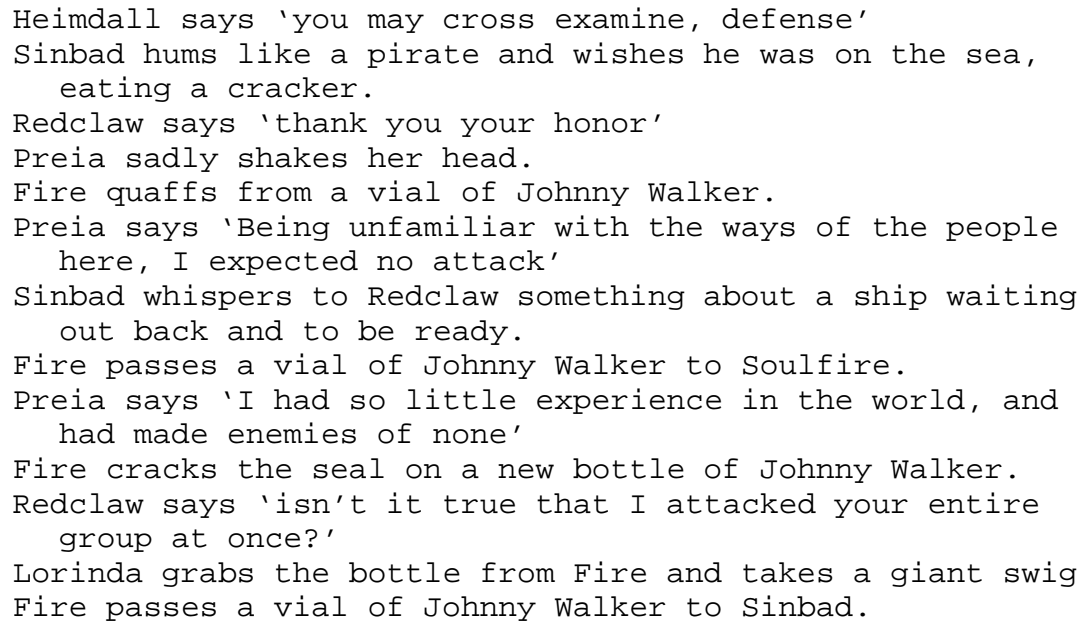




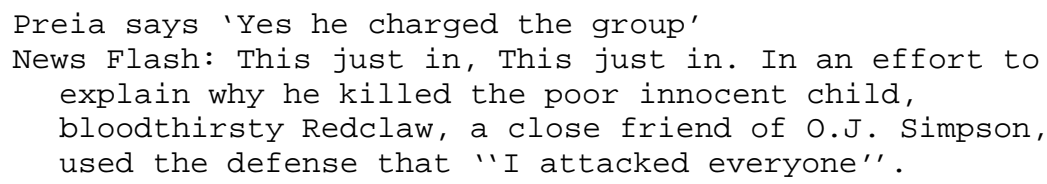

For those unfamiliar with MUDs in general, this is the result of players' creating a scene as they go. In the example, the participants use a range of "tell", "say", "yell", and similar commands to utter phrases, but these commands merely communicate what the user writes. While users also have a long list of "social" commands that are essentially pre-canned statements, few socials are being used here. Instead the participants are creating a shared scenario through their own play.

Illusion shares this sense of playfulness and word play with other MUDs. However, unlike other studied MUDs (e.g., Cherny's ElseMOO), there are few personal disclosures, intellectual arguments, political discussions, or similar conversations. Almost all exchanges concern the game; social interaction is intrinsically tied to the game structure. While exhibiting the above sense of playfulness, the predominant dimension of activity in combat play centers on cooperation and conflict behavior. We next turn to examining cooperation in Illusion's social world.

\subsection{SOCIABILITY AND COOPERATION}

Many interactions on Illusion are friendly and sociable. For example, players greet one another over the OOC channel when they login to the MUD. These greetings are directed at everyone, and individuals say hello back. Yet, these brief exchanges may be the only interaction one has with many players. Another form of public sociability is shown when mortals advance to the next level; players typically use the "grats" channel to acknowledge the accomplishment. People also answer one another's questions:

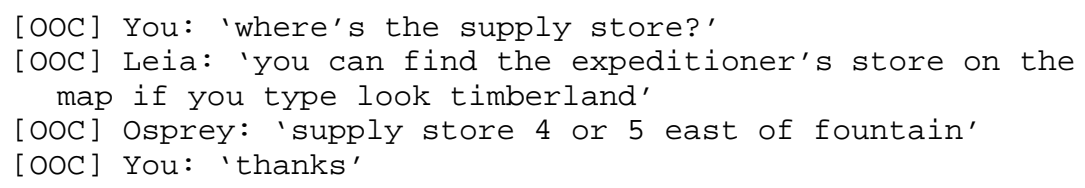

Individuals also show this sociability and cooperation towards specific others. Players perform services (such as enchantments or magic travel) and provide equipment to the needy, usually without remark or explicit repayment.

The game has many occasions where players cooperate with one another to play. We have already given examples with groups and cohesive clans. As a further example, the social activities centered around death provide occasions for cooperation. In Illusion, a mortal character "dies" when he receives more damage inflicted by mobs or other players than he can handle. When a character dies, he is not permanently deleted from the game. Instead, he finds himself with his previous scores in a special location, the Temple. However, his equipment and money are 
still on his "corpse", which remains where he died. He must retrieve the corpse and his belongings within a certain time period, since the corpse decays.

This is not straight-forward in the game. If the monster that killed a player is aggressive and remains near the corpse, the player may not be able to just go to the corpse before it decays. His hit points will be very low (only 1) and as mentioned, he will have little or no equipment (e.g., weapons, armor). He is very weak and thus highly susceptible to dying once again. Even if he safely reaches the corpse, his belongings may have already been taken by another player or by a looting mob.

Recovering a corpse, however, is much easier with help from other players. This assistance takes many forms: locating the corpse, killing the monster that killed the player in order to secure the corpse, "guarding" a character's corpse, transporting the character to his corpse, or even retrieving a character's items from the corpse and delivering them to the player in a safer area. Moreover, a player who is not able to retrieve his corpse in time finds himself dependent on others' goodwill for armor and other equipment.

As might be expected, a good deal of interaction occurs around these situations. In the following, Durendal (the author's character) has died. Steele, who was with Durendal, tells him that he will need the invisible spell ("invis") to get his corpse back. Durendal acknowledges this, noting that there are aggressive ("aggro") mobs, and asks for help from Torch, a more powerful character with the ability to render Durendal invisible:

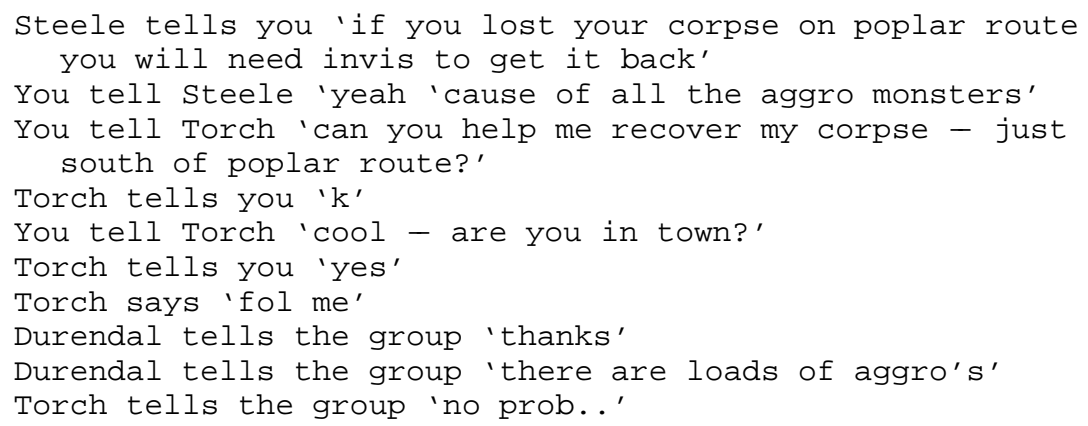

This was the beginning of several adventures for Durendal and these other characters. Indeed, often players perform these services gratis and at considerable risk to themselves.

\subsection{SOCIABILITY AND DISCLOSURE}

Despite this general air of friendly cooperation, Illusion's sociability is muted. If personal disclosures foster friendships (as Gabarro, 1990 argues), most relationships on Illusion cannot be said to be very deep. Almost all attempts to deepen personal knowledge of other players were rebuffed. This was not limited to the authors' interactions. In the following exchange, a direct personal question was dropped, as frequently occurred on this MUD: 


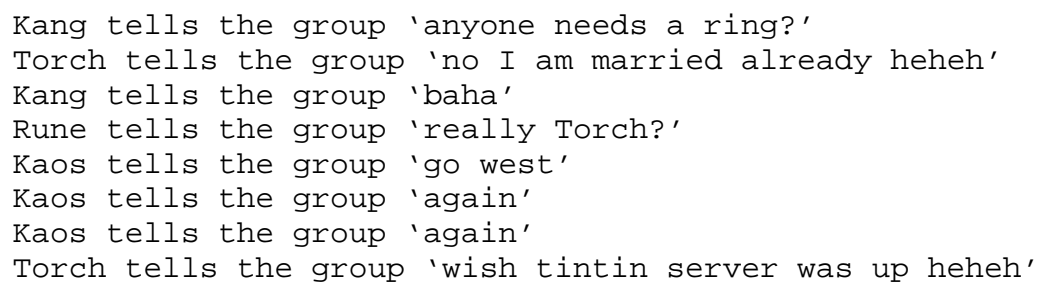

This directly contradicts the findings from studies of social MUDs and even some combat MUDs (e.g, Masterson, 1994; Ito, 1994), and was quite surprising to us. Nonetheless, this lack of sociability was noted by even players during the study:

Drake: 'everyone here rocks though they aren't too talkative'

and

[OOC] Peryl: 'You people aren't very talkative, are you?'

Of course, this is not uniformly true of all players. Three players, all female characters, engaged in a considerable amount of personal disclosure, even over public channels. For example, in the following, Anastasia has been discussing Arizona life and missing her boyfriend. On a previous day, she mentioned that her boyfriend attends Arizona State, so this is known to Voodoo:

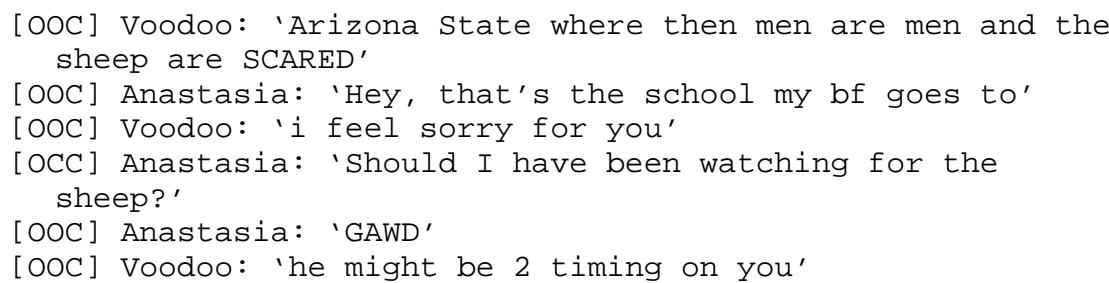

Others engaged in minor amounts of personal disclosure, often concerning real-life ("RL") relationships. For example, it became clear that two players were brothers and three others went to the same school, playing next to one another. Moreover, little details tended to come out, as one might expect, in game activity. For example, one character reported:

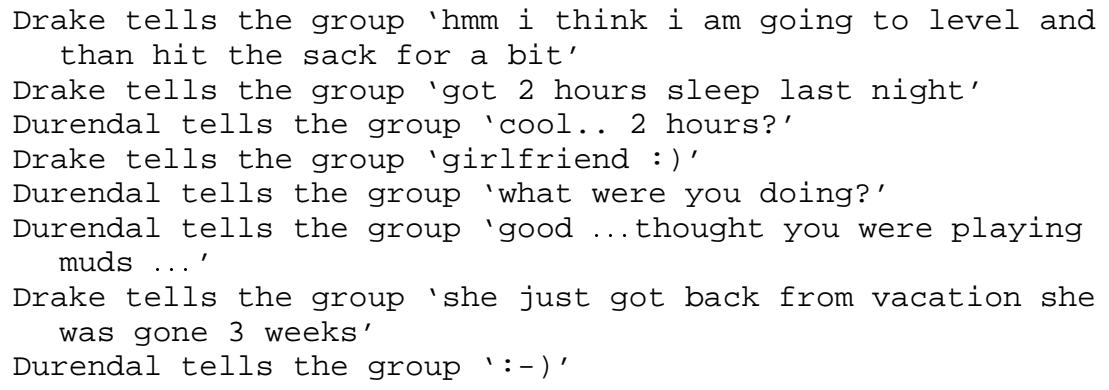


Another character occasionally complained about his wife, and yet another once revealed that he was a clerk at a Target department store. Yet, with the exception of several players, details were hesitantly or seldom revealed. Furthermore, sustained conversations of any sort were rare. This lack occurred not merely on the public channels, where contention for airtime might have been a factor. It was also present in rooms and through private communications.

Because the lack of personal disclosures and intimate conversations is so contrary to other studies, several possibilities need to be considered:

- Our character could have been an outcast and ignored. This did not appear to be the case, since we had different characters over the period of observation, and each appeared to be trusted. They were part of many groups and clans, engaging in a large number of game interactions. Furthermore, we also did not observe intimate or sustained conversations in rooms through which we passed (i.e., among other MUD participants), and there were few, if any, secondary indications that these conversations had occurred (e.g., references to previous conversations). Nor did other players indicate they knew more about other MUD players (i.e., who were not real-life acquaintances) than we did.

- Players on Illusion often had multiple characters, and the lack of a stable relationship between players and characters could have impeded intimacy. As mentioned, we had four characters over the period of observation, although we played only one during any given period. Other players played multiple characters simultaneously, although not during the same session. (Multi-playing characters at the same time is forbidden on Illusion and is strongly enforced as cheating.) Ambiguity in the composition of the audience does prevent disclosure (Goffman, 1961). However, other anonymous situations foster disclosures, as many studies have found (e.g., Turkle, 1995).

Additionally, people were able to distinguish at least some players from their characters, leading to what should have been a sense of identity:

Kretzkin tells you 'have you heard about Gandalf? (It's Firebrand)'

Or

Someone says 'and Kronos/Vanguard is really believable'

- Some amusement worlds may lack a sense of intimacy, and their participants may approve. Although Illusion maybe aberrant even for combat MUDs, some other amusement worlds also lack this sense of knowing the person outside of the setting. Indeed, the literature is quite conflicted about whether members of bars know much about one another. Anderson found that people regularly disclose personal details in the "barroom" or public part, as well as among regular members in the back:

As Simmel indicates, it seems easier to divulge personal information to strangers than to close peers, particularly information deemed "harmful". It is easier ... in part because most of the visitors don't see one another 
again as buddies and thus may not have an immediate interest in status competition. In a social and emotional sense, their passing relationships can be very open to certain kinds of personal information (Anderson, 1978, p. 10).

Katovich and Reese (1987) suggest as much in their bar ethnography, and certainly the CMC literature (e.g., Correll, 1995) is rife with intimate and personal discussions. On the other hand, Cavan found that few people talked about their outside biographies and work in her study of 100 San Francisco bars. Her findings have been contested, but it is interesting that this student of Goffman found so little disclosure. Similarly, Hayano (1982) found that few poker players knew much about others: "Many players come and go with few gestures toward sociability; they be known only by their first names, initials, or faces" (p. 102). He also pointed out that "... players seem to show little interest in the outside-of-the-cardroom lives of other players" (pp. 45-46).

Conceivably, each amusement world will have its own culture including norms for sociability. The early Chicagoans had a notion of an ecology of neighborhoods and other social worlds, where each existed in its own culture because of and through its relationship to other social worlds (Park, 1952; Bulmer, 1984). Similarly, on the Net, some collectivities will have great sociability and others very little. Members will self-select appropriately, reinforcing the cultures. In fact, because each collectivity can garner members from anywhere, there may be a great diversity of social environments, and it may be quite difficult to distinguish general social characteristics for these systems.

With MUDs, it is important to distinguish between social and sociable, as well as sociable and intimate. Illusion, like all combat MUDs, is clearly social, since one must engage in social activity to play the game. The social activity, nonetheless, is skewed towards that required by combat play. Illusion is also sociable, although as this section has indicated, the sociability is muted. Illusion has remarkably few personal disclosures, intimate conversations, or even long, non-game discussions. One can have a social world that is barely sociable, and a sociable world need not be intimate.

We next to turn to another type of social interaction, conflict.

\section{Conflict}

While sociability may be muted on Illusion, conflict is not. For a large number of players, the MUD means conflict as much as cooperation and friendship. There is often a semi-friendly, semi-hostile banter among participants:

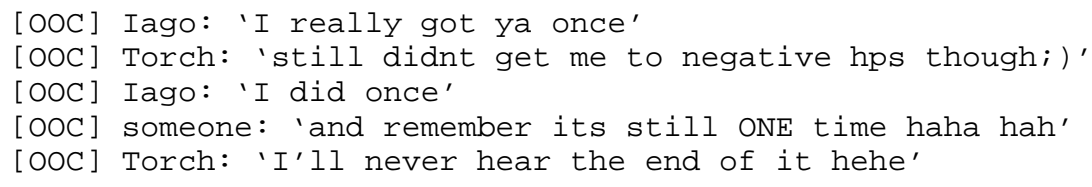


This is not completely derisive or conflictual behavior. Anderson found this type of banter between males who were the most friendly (within his "regulars" group as well as in the socially more marginal group "hoodlums"). Suttles also found this behavior among gang members:

Often they talk about each other, and there is a good deal of boasting and insulting anecdotes (Suttles, 1968, p. 184).

Suttles suggests that this social interaction affirms one's place in a cluster of "reps" or reputations in the absence of elaborated roles. Indeed, this vying may be a hallmark of adolescent male behavior (although most Illusion participants were college-age or older).

The threat of escalation into actual conflict was always present on Illusion. Sometimes, the banter would escalate:

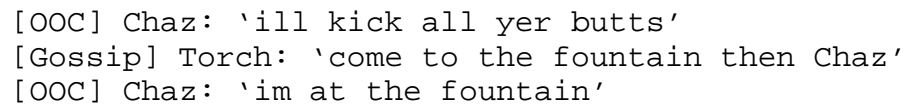

Or one might run into someone hostile while playing. In the following, Slider is a first level (i.e., a newbie) who makes the mistake of sizing up Kaos, a mid-level player:

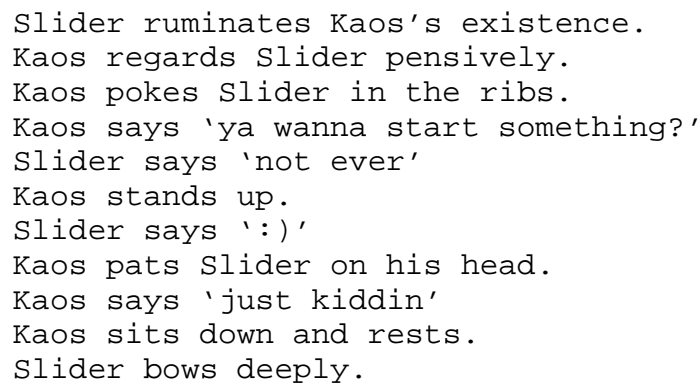

This threat of conflict was always present. At times, it escalated to the final stage:

[OOC] Kain: 'what happened Iago?'

[OOC] Iago: 'I got stilettos in me'

Game violence against other players was not uncommon. While player killing was not the norm on Illusion (unlike some combat MUDs), it was not atypical either. Players had remarkably few venues of violence and revenge. Players do not own rooms, businesses, or other system objects which can be destroyed. They are reduced to "killing" one another and perhaps taking their opponent's equipment.

Because player killing as a social activity is so unusual and because it serves to explicate social activity's relationship with entertainment, system rules, and game management, the next section discusses player killing in more detail. 


\subsection{PlAYER KILLING}

The act of killing another player's character is commonly referred to as player killing ("pk" or "pkilling"). Although not practiced as widely on Illusion as on some combat MUDs, player killing is standard on Illusion:

[OOC] Glyph: 'this is a pk mud ...'

Player killing is considered central to the game, as exercised by some players on Illusion. Although there are combat MUDs where player killing is discouraged, this is not the case on Illusion, as one player's bulletin board note attests:

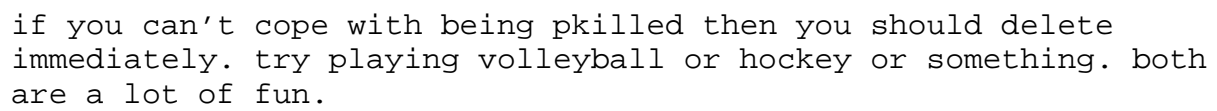

If one thing can be said with certainty about player killing, it is that players have numerous different motivations for engaging in this activity. Some players appear to derive great pleasure and satisfaction from killing other players' characters. The reasons players find such activity pleasurable are undoubtedly numerous and complex. However, we have observed several striking reasons:

- A considerable amount of player killing occurs because of previous grudges or player killing. While some player killing occurs to garner equipment (by stealing it, or "looting"), most occurs out of a sense of revenge. When one player gripes about being killed, another points out that it was appropriate:

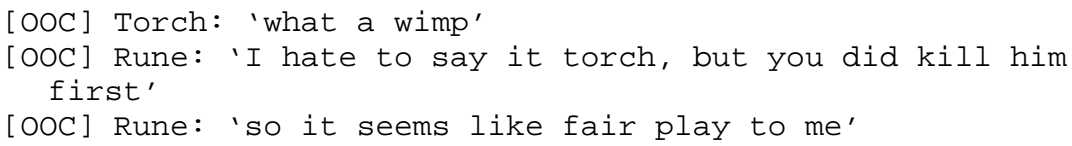

The ultimate form of revenge is to pkill the character, take his equipment, and then destroy the corpse ("sac the corpse"). Although this does not destroy the other character, it does require him to start collecting equipment and money again.

- Player killing is a form of vying over one's reputation, just as is verbal banter. Sometimes participants simply recounted their total kills, and sometimes kills against one another:

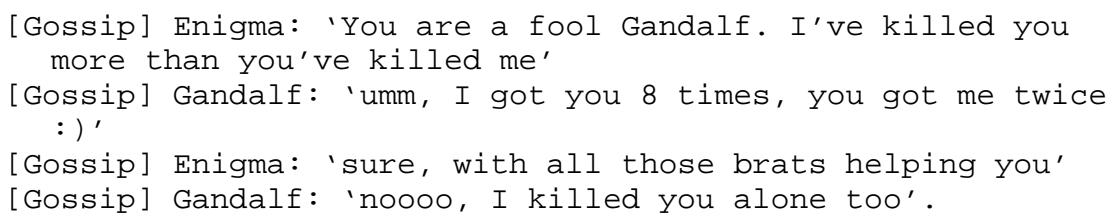

Players also established and acknowledged relative positions through player killing.

- Many high-level players focus on killing other players' characters rather than leveling their character or exploring the MUD. Being very familiar and accustomed to Illusion's world, the standard challenges and attractions no longer 
excite or compel as they once did. It can be much harder to kill other players than mobs, and for high level players, player killing provides new excitement:

[OOC] Glyph: 'big problem is that when you hit the really

high levels there isn't much to do but kill others'

This can extend to mid-level players as well. Player killing is more challenging, especially for experienced players. While some truly dislike being pkilled, it provides a sense of novelty and excitement for the person doing it:

[OOC] Grifter: 'no ...i kill cuz i was bored'

Some participants were noted for player killing. Interestingly, these were often not considered social deviants by others. Some were seen as powerful, attractive members, such as Gandalf in the earlier example:

[Gossip] Gandalf: 'umm, I got you 8 times, you got me twice :) '

Becoming a proficient player killer is quite difficult. It requires a thorough understanding of the intricacies and subtleties of a MUD and its combat system, a knowledge of unique tactics when playing against a human opponent, and a certain amount of cunning and guile. Players who might want to kill another character may refrain from doing so if they feel their combat skill is lacking, and player killing for many, but not all, signals a level of MUD proficiency. This skill is often very desired. For example, when asked by a friend to kill another player (because of level restrictions, below), a low-level player eagerly started to ask for instructions and strategies. Since once a player starts to player kill, it may be very difficult to avoid future combat, this cycle tends to reinforce the backdrop of constant conflict on the MUD.

\subsection{CODE AND PLAYER KILLING}

Player killing clearly provides novelty and entertainment. Yet it also brings management challenges. Killing newbies and unfair fights discourage the recruitment and retainment of new members. The collectivity cannot socially maintain itself, and management must either assert itself or find a dying collectivity. Many systems that permit player killing, therefore, place restrictions on this activity, and Illusion is no exception. These restrictions are managed, and are both social and code-based.

Illusion currently employs three basic restrictions on player killing. The first is that newbies (i.e., characters under level nine) cannot be killed by another player, nor can they engage in player killing. This provides a safety zone for new characters. Without this restriction, it would be harder to recruit new players to the MUD. This rule has remained consistent through our observation period, and despite the court trial presented above, appears to work in general. Interestingly, this restriction is enforced socially rather than through code: Violations are taken to an immortal, who then punishes the pkiller. 
The second restriction allows players to choose whether they wish to participate in player killing. This is accomplished by limiting player killing to characters who are members of a clan. That is, a pkill attempt is only legal if both the aggressor and the intended target are both members of a clan; thereby, a character cannot be legally killed if he has never engaged in player killing himself and is not a member of a clan. This restriction is enforced largely socially, although there is a minor technical support for it. If a non-clanned character attacks another character, the system will automatically mark the aggressor as a member of the "loner" clan. A loner can then be legally killed by any clanned or loner character. However, if a clanned character attacks a non-clanned character, the aggressor is subject to social action: If caught, he will be punished by an immortal. Note that with this rule, a player is faced with a tradeoff between obtaining the social activity of a clan versus the risk and trauma of player killing.

The third restriction applies to "out of level" ("OOL") player killing. While many factors affect the outcome of a fight, a character that is significantly higher in level than his target will have a definite advantage and will probably be victorious. There is technical support in place to counterbalance this advantage. If the aggressor is more than eight levels higher than the intended target, he will automatically lose experience points (i.e., his score will be lowered). Algorithmically, the greater the level difference, the greater the penalty. It is possible for a character to lose several levels as a result of OOL player killing. This is a significant penalty because levels represent a considerable time investment. The penalty, then, does not prevent lopsided fights, but it does discourage them. An aggressor must weigh the desire to kill a lower level player against the resultant experience loss.

Prior to this technically-enforced restriction, attempts to limit OOL player killing were enforced socially: An aggressor more than six levels higher than his opponent was subject to trial. The threat of social enforcement, however, was not a very effective deterrent; high level characters frequently killed characters who were considerably lower in level.

[OOC] someone: 'yeah well we've lost a LOT of players due to OOL Pking'

Many players apparently engaged in OOL player killing with the knowledge that they would probably be able to avoid punishment. Since the OOL restriction is now enforced by code, punishment is certain. This technical solution is more effective than the original social rule. Players may still kill OOL (preserving some of the social ambiguity of the original situation), but are punished automatically. There is really no way to avoid punishment; the system sees any and all infractions and consistently punishes the offending character accordingly. The fact that it is enforced directly in the code appears to contribute significantly to the restriction's efficacy as a deterrent.

These three restrictions show three different responses by Illusion's management and highlight the complex interplay among the need for novelty and entertainment, the issues of managerial control, and potential technical fixes. As we noted, player 
killing provides entertainment and novelty. Unfortunately, it also brings problems of social maintenance that need to be addressed in some manner.

In the case of newbie killing, the situation was sufficiently unproblematic that no new solutions have been proposed during the observation period (perhaps because killing newbies is not interesting for experienced players). In the case of allowing people to avoid being pkilled, management had to act in order to retain those players (and consciously decided what kind of sociality they wanted). Players opposed to player killing were essentially clustered. However, the underlying code base has no obvious mechanism to cluster players outside of clans, and so the clan mechanism was used. The unfortunate consequence is that management, in order to protect some players, restricted their social interactions. (It is interesting that the immortals did not just prevent attacks on these players. They decided on an alternative solution, which must be more complex in terms of the code. They did so to allow greater social ambiguity, which they believed would result in greater social verisimilitude and therefore a better game.)

The final situation, that of out-of-level fights, was fixed with a technical solution. The original social mechanism, that of taking offenders to trial or having immortals punish the offender, was not working, largely because it overwhelmed Illusion's management. Again, the technical mechanism maintained a level of social ambiguity; players can still pkill out-of-level, but the system punishes them for it. Punishment is certain, and Illusion's management no longer needs to examine each case.

The findings of O'Day et al. (1996) carry here. Technical and social solutions exist in a tradeoff space, and no one tradeoff is true for all situations. It is the management's requirement to balance potential solutions against potential consequences. Some consequences cannot be foreseen (e.g., having pkillers keep multiple characters at different levels to avoid the original out-of-level restriction), and management must rebalance the situation appropriately. However, the constant need for novelty and entertainment change O'Day, Bobrow, and Shirley's situation; the relentless requirement for change and improvement make it much more difficult to consider solutions and their consequences.

All of these situations and solutions were mediated by the time commitments and skill levels of Illusion's management. They are volunteers, with limited time, although a large number of these issues could have easily overwhelmed professional management as well. Illusion's immortals have many responsibilities, including constructing new and interesting things to retain the mortals (such as new mobs to fight and new MUD areas to explore). The constant push for novel entertainment, as well as competition with other amusement worlds, always interacts with their ability to maintain the MUD collectivity. In important ways, it is amazing that Illusion works at all, either technically or socially. 


\section{The social world of a combat MUD}

This paper has examined how the social world of a game system is arranged. Games are often about allowing people to practice specific physical behaviors, intellectual mechanisms, or social interactions in a manner that is simplified and almost ritualistic. It is difficult to generalize from one setting, but Illusion, and we believe other amusement worlds as well, accordingly simplify certain aspects of everyday life in ways that their participants find intriguing. One of these simplifications is in the social interaction and activity within the game. As we have noted, social activity is designed into Illusion. Yet, all of the social structures are rudimentary and simplified. As an example, the auction system in this amusement world is only a vestige of the multi-tiered, multi-faceted exchange networks in everyday life. We have also seen that the social interactions predominate on conflict and cooperative behavior. While the interactions can be substantial, they are largely restricted to this range. Therefore, while social activity is designed into Illusion, and is an intrinsic part of its game and entertainment, Illusion is a highly simplified social world and this is no doubt part of its attraction.

Several points should be stressed about this type of computing:

- Computing in this environment is quite different than in work settings. In work settings, it has been argued (for example, in Suchman and Wynn, 1984) that designers must find ways to avoid destroying the full complexity and nuanced activity of work life. Within Illusion, however, some of the restrictions and constraints appear to be useful, if not attractive, to game players. They provide a sense of control, allowing participants to engage in play - play that allows users to practice and explore particular types of social interaction. In addition, Illusion and other amusement worlds need a constant infusion of new capabilities, not because they provide additional efficiencies and functional improvements, but rather because they entertain and exhilarate participants.

- Entertainment environments, or at least some amusement worlds, most likely differ from sociable computing (as in social MUDs and chat systems). We note that activity on a system can be social without being sociable. Illusion is clearly social, but its sociability is muted and limited. It is certainly not an intimate world, with lively, personal conversations and rapidly deepening friendships, as much of the CMC literature portrays virtual collectivities and online life.

- As many CSCW researchers (e.g., Orlikowski, 1992; Bowers, 1994) have found, the actual technical implementation is often less important than the managerial use of the system. As we have shown above, management is key in many forms of social control and maintenance on Illusion; the immortals hold the power to create and enforce rules, both socially and technically. Managerial control of amusement worlds is likely to be as critical as for information systems, if Illusion is a fair example. The effects of management decisions on Illusion clearly outweighed the effects of any specific implementation, 
but the technology constrained the potential solutions available to Illusion's management.

Illusion is often an engrossing social world for its participants. The game is about acquisition and conflict, two popular themes in all of Western mass culture. But, for many participants, the social activity is key. This paper has explored Illusion's social world accordingly, describing its social structures, activities, and interactions in their relation to the goal of entertainment, a managed social life, and the technical base. In this, we noted some important differences from even Illusion's close cousins, social MUDs. To properly understand the entire range of virtual communities and collectivities, then, more studies of similar environments will be required.

\section{Acknowledgements}

This paper benefited greatly from conversations with Lynn Cherny, Erik Ostrom, and Marc Smith, as well as Clayton Lewis, Wendy Kellogg, and others at the Human-Computer Interaction Consortium workshop. Paul Dourish and the anonymous reviewers considerably helped this paper along. In addition, the other members of our research team, Wayne Lutters and Dave McDonald, contributed greatly towards our understanding of game MUDs and other Net phenomena. We also thank Winnie Hui for her work on the interview data; her bachelor's thesis contributed to our understanding of MUD use.

\section{References}

Ackerman, Mark S. and Leysia Palen (1996): The Zephyr Help Instance: Promoting Ongoing Activity in a CSCW System. In Proceedings of the ACM Conference on Human Factors in Computing Systems (CHI' 96). Reading, MA: Addison-Wesley, pp. 268-275.

Anderson, Elijah (1978): A Place on the Corner. Chicago: University of Chicago Press.

Avedon, Elliott M. and Brian Sutton-Smith (1971): The Study of Games. New York: John Wiley \& Sons.

Bartle, Richard (1990): Interactive Multi-User Computer Games. Report to British Telecom, manuscript, MUSE Ltd., London.

Bowers, John (1994): The Work to Make a Network Work: Studying CSCW in Action. In Proceedings of the ACM Conference on Computer-Supported Cooperative Work (CSCW'94). New York: ACM Press, pp. 287-298.

Bruckman, Amy (1992): Identity Workshops: Emergent Social and Psychological Phenomena in TextBased Virtual Reality. Manuscript, Massachusetts Institute of Technology, Media Lab, Cambridge, MA.

Bulmer, Martin (1984): The Chicago School of Sociology. Chicago: University of Chicago Press.

Busey, Andrew (1995): Secrets of the MUD Wizards. Indianapolis: Sams.net Publishing.

Cavan, Sherri (1966): Liquor License: An Ethnography of Bar Behavior. Chicago: Aldine.

Cherny, Lynn (1995): The Mud Register: Conversational Modes of Action in a Text-Based Virtual Reality. Ph.D. dissertation, Department of Linguistics, Stanford University, Palo Alto, CA.

Clarke, Adele E. (1991): Social Worlds/Arenas Theory as Organizational Theory. In D.R. Maines (eds.): Social Organization and Social Process: Essays in Honor of Anselm Strauss. New York: Aldine de Gruyter, pp. 119-158.

Collier, Gary, Henry L. Minton and Graham Reynolds (1991). Currents of Thought in American Social Psychology. New York: Oxford. 
Conquergood, Dwight. 1994. Homeboys and Hoods: Gang Communication and Cultural Space. In L.R. Frey (eds.): Group Communication in Context: Studies of Natural Groups. Hillsdale, NJ: Lawrence Erlbaum Associates, pp. 23-56.

Correll, Shelley (1995): The Ethnography of an Electronic Bar. Journal of Contemporary Ethnography, vol. 24, no. 3, pp. 270-298.

Crawford, Chris (1984): The Art of Computer Game Design. Berkeley: Osbome/McGraw-Hill.

Cressey, Paul G. (1969): The Taxi-Dance Hall: A Sociological Study in Commercialized Recreation and City Life. Montclair, NJ: Patterson Smith.

Curtis, Pavel and David A. Nichols (1993): MUDs Grow Up: Social Virtual Reality in the Real World. Manuscript, Xerox Parc, Palo Alto, CA.

Davis, Fred (1968): Professional Socialization as Subjective Experience: The Process of Doctrinal Conversion among Student Nurses. In H.S. Becker, B. Geer, D. Riesman, and R.S. Weiss (eds.): Institutions and the Person: Papers Presented to Everett C. Hughes. Chicago: Aldine, pp. 235251.

Duneier, Mitchel (1992): Slim's Table. Chicago: University of Chicago.

Erikson, Erik (1975): Configurations in Play: Clinical Notes. New York: Arno Press.

Fine, Gary A. (1983): Shared Fantasy: Role-Playing Games as Social Worlds. Chicago: University of Chicago Press.

Fine, Gary A. (1995). A Second Chicago School? The Development of a Postwar American Sociology. Chicago: University of Chicago Press.

Gabarro, John J. (1990): The Development of Working Relationships. In J. Galegher and R. Kraut (eds.): Intellectual Teamwork: Social and Technological Foundations of Cooperative Work. Hillsdale, NJ: Lawrence Erlbaum, pp. 79-110.

Goffman, Erving (1961): The Presentation of Self in Everyday Life. New York: Anchor-Doubleday.

Hayano, David M. (1982): Poker Faces: The Life and Work of Professional Card Players. Berkeley: University of California Press.

Hewitt, John P. and Myrna L. Hewitt (1986): Introducing Sociology: A Symbolic Interactionist Perspective. Englewood Cliffs: Prentice-Hall.

Ito, Mimi (1994): Cybernetic Fantasies: Extended Selfhood in a Multi-User Dungeon. Stanford University, Palo Alto, CA.

Ito, Mimi (1995): Cyborg Couplings in a Multi-User Dungeon. Manuscript, Stanford University, Palo Alto, CA. http://www.portola.com/PEOPLE/mito/couplings.html.

Ito, Mizuko (1997): Virtually Embodied: The Reality of Fantasy in a Multi-User Dungeon. In D. Porter (eds.): Internet Culture. New York: Routledge, pp. 87-110.

Jones, Steven G. (1995): CyberSociety: Computer-Mediated Communication and Community. Thousand Oaks, CA: Sage.

Katovich, Michael A. and William A. Reese (1987): The Regular: Full-Time Identities and Memberships in an Urban Bar. Journal of Contemporary Ethnography, vol. 16, no. 3, pp. 308-343.

Lewis, Clayton (1982): Using the "Thinking-aloud" Method in Cognitive Interface Design. Research Report, RC 9265, IBM Thomas J. Watson Research Center, White Plains, NY.

Masterson, John (1994): Ethnography of a Virtual Society: Or, How a gangling, wiry half-elf found a way to fit in. Manuscript, University of Montan. ftp.game.org/pub/mud/text/research/ethno.txt.

Meckel, Mary V. (1988): Continuity and Change within a Social Institution: The Role of the TaxiDancer. Ph.D. dissertation, Sociology Department University of Nebraska - Lincoln.

Meltzer, Bernard N., John W. Petras, and Larry T. Reynolds (1977): Symbolic Interactionism: Genesis, Varieties, and Criticism. Boston: Routledge \& Kegan Paul.

Miles, Matthew B. and A. Michael Huberman (1994): Qualitative Data Analysis. Thousand Oaks, CA: Sage.

Mynatt, Elizabeth D., Vicki L. O’Day, Annette Adler, and Mizuko Ito (1997): Network Communities: Something Old, Something New, Something Borrowed. Computer-Supported Cooperative Work: The Journal of Collaborative Computing, vol. 7, no. 1, pp. 123-156.

O’Day, Vicki, Daniel Bobrow, Kimberly Bobrow, Mark Shirley, Billie Hughes, and Jim Walters (1998): Moving Practice: From Classrooms to MOO Rooms. Computer-Supported Cooperative Work: The Journal of Collaborative Computing, vol. 7, no. 1, pp. 9-45. 
O’Day, Vicki L., Daniel G. Bobrow, and Mark Shirley (1996): The Social-Technical Design Circle. In Proceedings of the ACM Conference on Computer-Supported Cooperative Work (CSCW'96). New York: ACM Press, pp. 160-169.

Orlikowski, Wanda J. (1992): Learning from Notes: Organizational Issues in Groupware Implementation. In Proceedings of the Computer Supported Cooperative Work (CSCW'92). New York: ACM Press, pp. 362-369.

Park, Robert E. (1952): Human Communities: The City and Human Ecology. Glencoe, IL: Free Press.

Prus, Robert and Styllianoss Irini (1980): Hookers, Rounders, and Desk Clerks. Toronto: Gage Publishing.

Reid, Elizabeth (1991): Electropolis: Communication and Community on Internet Relay Chat. Manuscript, Department of History, University of Melbourne, Melbourne.

Reid, Elizabeth (1994): Cultural Formations in Text-Based Virtual Realities. Manuscript, Department of History, University of Melbourne, Melbourne.

Rheingold, Howard (1993): The Virtual Community. Reading, MA: Addison-Wesley.

Roebuck, Julian (1986): Sociability in a Black Outdoor Drinking Place. Studies in Symbolic Interaction, vol. 7, no. A, pp. 161-197.

Schwartzman, Helen B. (1978): Transformations: The Anthropology of Children's Play. New York: Plenum Press.

Shah, Rawn and James Romine (1995): Playing MUDs on the Internet. New York: Wiley.

Smith, Marc A. (1993): Voices from the WELL: The Logic of the Virtual Commons. Manuscript, UCLA, Sociology Department, Los Angeles.

Sproull, Lee and Sara Kiesler (1991): Connections: New Ways of Working in the Networked Organization. Cambridge, MA: MIT Press.

Strauss, Anselm (1991): Creating Sociological Awareness: Collective Images and Symbolic Representations. New Brunswick: Transaction.

Strauss, Anselm L. (1987): Qualitative Analysis for Social Scientists. New York: Cambridge University Press.

Strauss, Anselm L. (1993): Continual Permutations of Action. New York: Aldine de Gruyter.

Suchman, Lucy and Eleanor Wynn (1984): Procedures and Problems in the Office. Office: Technology and People, vol. 2, pp. 133-154.

Suttles, Gerald D. (1968): The Social Order of the Slum. Chicago: University of Chicago Press.

Sutton-Smith, Brian (1976a): A Children's Games Anthology: Studies in Folklore and Anthropology. New York: Arno Press.

Sutton-Smith Brian (1976b): The Games of the Americas. New York: Arno Press.

Turkle, Sherry (1995): Life on the Screen: Identity in the Age of the Internet. New York: Simon \& Schuster.

Wellman, Barry, Janet Salaff, Dimitrina Dimitrova, Laura Garton, Milena Gulia, and Caroline Haythornthwaite (1996): Computer Networks as Social Networks: Collaborative Work, Telework, and Virtual Communities. Annual Review of Sociology, vol. 22, pp. 213-238.

Whyte, William Foote (1993): Street Corner Society. Chicago: University of Chicago Press.

Williams, Raymond (1985): Keywords: A Vocabulary of Culture and Society. New York: Oxford University Press. 